\section{SOI: 1.1/TAS DOI: $10.15863 /$ TAS International Scientific Journal Theoretical \& Applied Science}

p-ISSN: 2308-4944 (print) e-ISSN: 2409-0085 (online)

Year: $2015 \quad$ Issue: 09 Volume: 29

Published: $30.09 .2015 \quad$ http://T-Science.org
Denis Alexandrovich Chemezov

Master of Engineering and Technology, Corresponding member of International Academy of

Theoretical and Applied Sciences, Lecturer of Vladimir Industrial College, Russia chemezov-da@yandex.ru

Anzhelika Vladimirovna Bayakina Lecturer of Vladimir Industrial College, Russia bajakina.anzhelika@yandex.ru

SECTION 7. Mechanics and machine construction.

\title{
THE STATE OF LOADED DETAILS BY RIVETED JOINT
}

Abstract: The article presents the character of the stress and strain of materials details by riveted joint under the action of multidirectional loads.

Key words: the riveted joint, deformation, biaxiality.

Language: Russian

Citation: Chemezov DA, Bayakina AV (2015) THE STATE OF LOADED DETAILS BY RIVETED JOINT.

ISJ Theoretical \& Applied Science 09 (29): 17-20.

Soi: http://s-o-i.org/1.1/TAS-09-29-4 Doi: crossef http://dx.doi.org/10.15863/TAS.2015.09.29.4

\section{СОСТОЯНИЕ НАГРУЖЕННЫХ ДЕТАЛЕЙ ЗАКЛЕПОЧНОГО СОЕДИНЕНИЯ}

Аннотация: B статье представлен характер напряжения и деформации материалов деталей заклепочного соединения при действии разнонаправленных нагрузок.

Ключевые слова: заклепочное соединение, деформация, биаксиальность.

Заклепка - это соединительный элемент, имеющий форму стержня, на котором с двух сторон выполняется головка различной формы [1].

Наиболее часто применяются заклепки с полукруглой головкой. Материалами заклепок являются стальные и цветные сплавы обладающие высокой пластичностью и прочностью.

Неразъемное соединение нескольких деталей заклепкой применяется в случаях действия на узел значительных вибрационных и ударных нагрузок, невозможности сваривания и ограничения нагрева материалов соединяемых деталей [2]. Данный способ соединения до сих пор применяется (как единственный рациональный или возможный) в авиастроении, в судостроении, в строительных сооружениях и в общем машиностроении.

Заклепка подвергается срезу, смятию и изгибу от действия разнонаправленных нагрузок (сил) на соединенные детали в одной или нескольких плоскостях [3]. Стержень заклепки деформируется (изгибается) в направлениях действия нагрузок. Возникают касательные напряжения, максимальная величина которых будет достигать в поперечном сечении стержня заклепки на стыке пересекающихся отверстий нагруженных деталей. Контактные напряжения между поверхностями стержня заклепки и двух отверстий приводят к смятию материалов деталей. Повторные нагрузки увеличивают деформацию и снижают прочность материалов заклепки и соединенных деталей. В результате приведенных возможных деформаций, стержень заклепки может частично или полностью разрушиться и тем самым произойдет разъединение заклепочного соединения.

Расчет напряженно-деформированного состояния деталей заклепочного соединения позволит выявить критические области нагруженных материалов и прогнозировать долговечность эксплуатации сборочной единицы.

Габаритные размеры и конфигурации заклепки с полукруглой головкой и двух соединяемых деталей (пластин) были приняты в соответствии с ГОСТ 10299-80 [4] и ГОСТ 1030480 [5]: диаметр стержня заклепки $d-16.0$ мм; диаметр головки заклепки $D_{3}-25.0$ мм; высота головки заклепки $H-9.5$ мм; радиус под головкой заклепки $r$ - не более 0.8 мм; радиус сферы головки заклепки $R-13.0$ мм; длина стержня заклепки $L_{3}-40.0$ мм; длина каждой соединяемой детали $L_{n}-80.0$ мм; ширина каждой соединяемой детали $B-80.0$ мм; толщина каждой соединяемой детали $h-20.0$ мм; диаметр сквозного отверстия в каждой соединяемой детали $D_{n}-16.1$ мм. 
На всех кромках деталей заклепочного соединения были выполнены радиусные фаски размером $r \quad 0.2$ мм. Материал заклепки и соединяемых деталей - сталь 10 ГОСТ 1050-88 [6].

Решение выполнялось в модуле Static Structural программного комплекса Ansys. Не изменяющиеся по величине нагрузки прикладывались в одной плоскости.
Длительность действия сил на поверхности деталей заклепочного соединения - 1.0 с. Разбиение твердотельных моделей заклепочного соединения было выполнено на 207355 конечных элементов.

Твердотельная модель заклепочного соединения в трехмерной постановке и действующие равные нагрузки представлены на рис. 1.

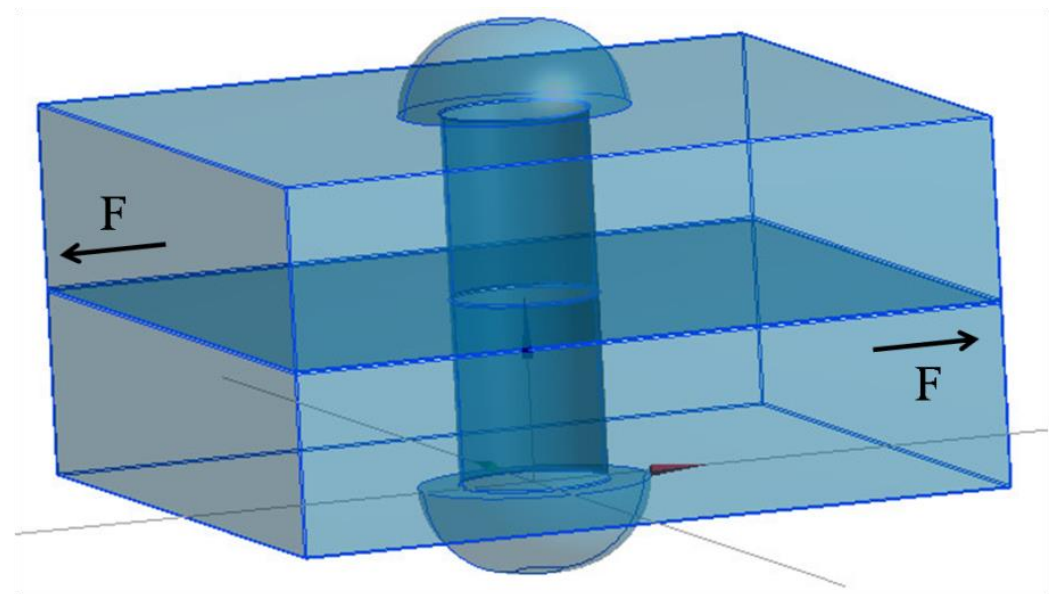

Рисунок 1 - Трехмерная модель заклепочного соединения. F - направление действия постоянной нагрузки.

Значения коэффициентов биаксиальности для каждой деформированной детали соединения представлены на рис. 2. Биаксиальность - это коэффициент, определяемый как отношение знакопеременного минимального напряжения к знакопеременному максимальному напряжению [7].
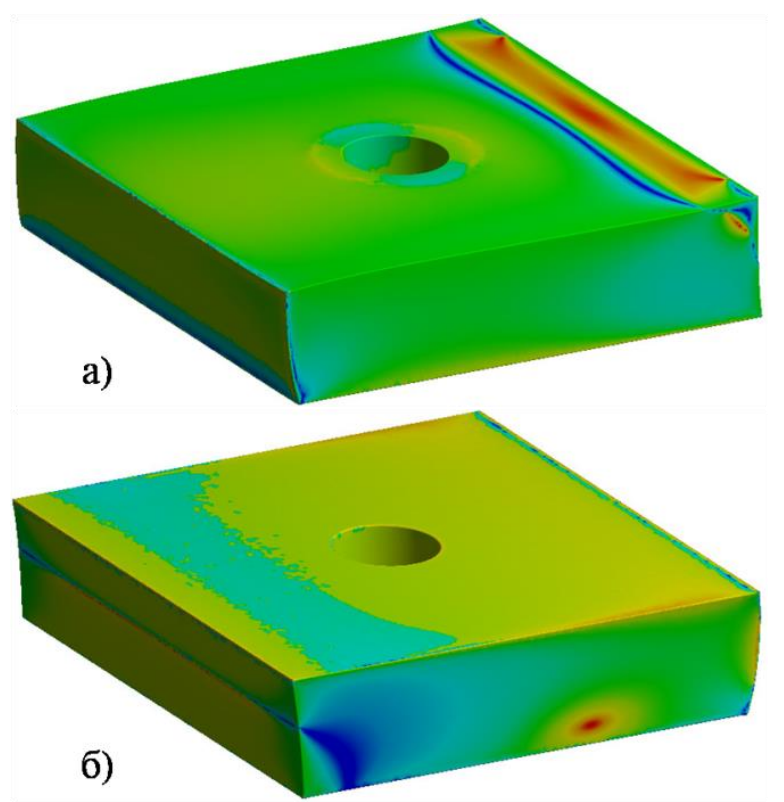

B)
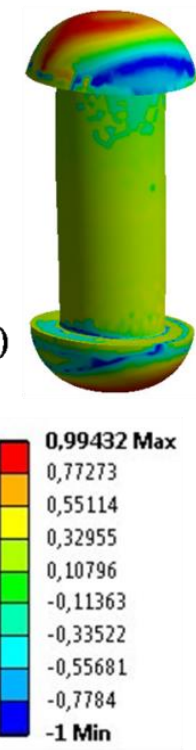

Рисунок 2 - Индикаторы биаксиальности: а - верхняя плита, б - нижняя плита, в - заклепка.

Расчетные величины коэффициентов биаксиальности составляют от 1.0 до -1.0. При коэффициенте биаксиальности, равном 1.0, первое, второе и третье напряжения (нормальные и касательные) в точке равны. С уменьшением значения коэффициента биаксиальности с 1.0 до 0 величина третьего главного напряжения уменьшается, а первого главного напряжения 


\begin{tabular}{|c|c|c|c|c|c|}
\hline Impact Factor: & $\begin{array}{l}\text { ISRA (India) } \\
\text { ISI (Dubai, UAF } \\
\text { GIF (Australia) } \\
\text { JIF }\end{array}$ & $\begin{array}{l}=1.344 \\
=0.829 \\
=0.356 \\
=1.500\end{array}$ & $\begin{array}{l}\text { SIS (USA) = } \\
\text { PUHЦ (Russia) = } \\
\text { ESJI (KZ) = } \\
\text { SJIF (Morocco) }\end{array}$ & $\begin{array}{l}=0.912 \\
=0.179 \\
=1.042 \\
=2.031\end{array}$ & ICV (Poland) \\
\hline
\end{tabular}

увеличивается. Аналогичные расчеты выполняются и для отрицательных значений коэффициентов биаксиальности. Положительные величины коэффициентов биаксиальности характеризуют растяжение материала детали, отрицательные - сжатие.

В соответствии с индикаторами биаксиальности, стержень заклепки подвергается растяжению. Значение коэффициента составляет 0.1..0.3. Головка заклепки находится в равнонапряженном состоянии: сжимающее действие на периферии и растягивающее действие ближе к оси детали. Поверхность отверстия верхней соединенной детали испытывает растяжение (желтый цвет на модели) и сжатие (голубой цвет на модели). Отверстие детали начинает вытягиваться в направлении действия силы. Отверстие нижней соединенной детали равномерно растягивается.

Таким образом, в исследуемой схеме нагружения заклепочного соединения большая интенсивность напряжения наблюдается в верхней соединенной детали.
Направление и интенсивность полной деформации каждой детали заклепочного соединения отображены на эпюрах векторов (рис. 3).

Полная деформация деталей заклепочного соединения рассчитывается как алгебраическая сумма линейной и угловой деформаций возникающих по трем координатным осям и плоскостям [8]

$$
\begin{aligned}
\varepsilon_{t o t} & =\left(\varepsilon_{x}+\frac{\alpha_{x y}+\beta_{x y}}{2}+\frac{\alpha_{x z}+\beta_{x z}}{2}\right)+ \\
& +\left(\varepsilon_{y}+\frac{\alpha_{y x}+\beta_{y x}}{2}+\frac{\alpha_{y z}+\beta_{y z}}{2}\right)+. \\
& +\left(\varepsilon_{z}+\frac{\alpha_{z x}+\beta_{z x}}{2}+\frac{\alpha_{z y}+\beta_{z y}}{2}\right),
\end{aligned}
$$

где $\alpha$ и $\beta$ - углы наклона граней элементарного параллелепипеда (продольное сечение формы стержня заклепки).
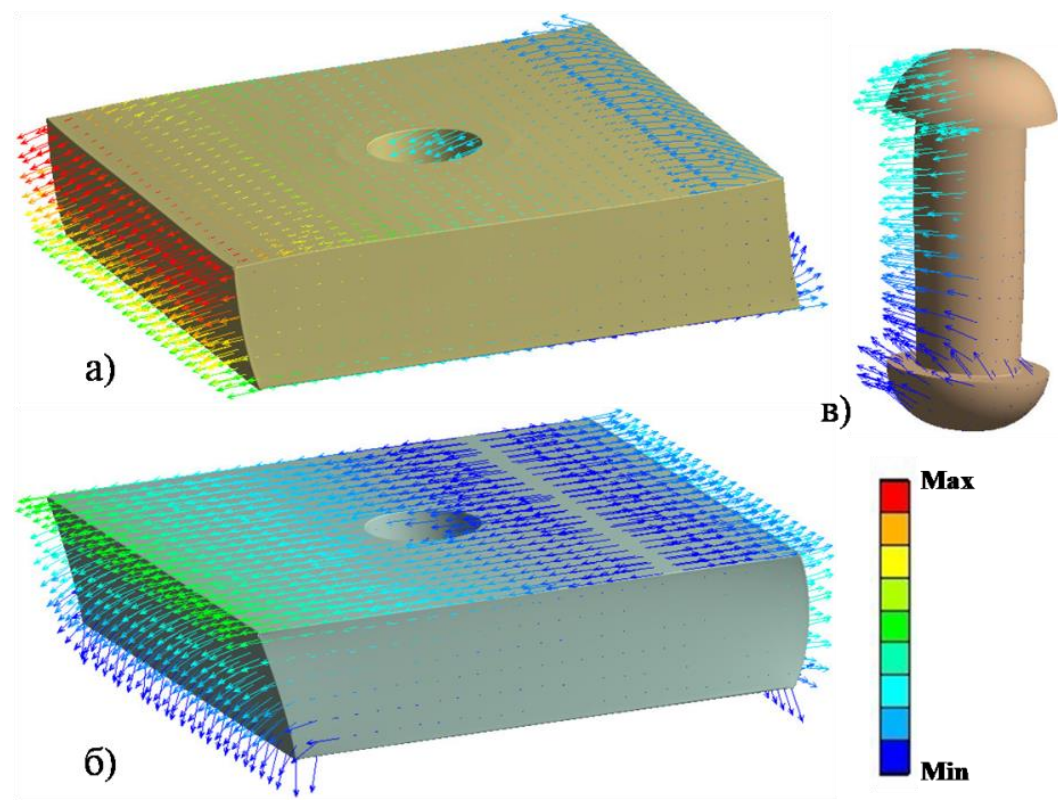

Рисунок 3 - Эпюры векторов полной деформации: а - верхняя плита, б - нижняя плита, в - заклепка.

Направление деформации материала заклепки соответствует направлению действия нагрузки на верхнюю деталь соединения. Можно отметить, что возможному разрушению неразъемного соединения будет способствовать значительные изменения геометрических форм верхней и нижней деталей. Ввиду того, что абсолютная деформация заклепки может иметь как положительные, так и отрицательные значения, то при суммировании деформаций, полная деформация на некоторых участках будет равна практически нулю. Срез (разрушение) заклепки в условиях неравномерной деформации может произойти в месте перехода диаметра стержня в буртик головки.

Представленная картина напряженнодеформированного состояния деталей заклепочного соединения внахлестку позволяет судить о запасе прочности соединительного элемента с учетом геометрических размеров стержня (длина и диаметр) и толщины пластин. Отношение деформации стержня заклепки к деформации поверхности детали, на которую действует нагрузка, составляет 1:3 (рис. 3 , а) и 1:2 (рис. 3, б) когда расстояние от края пластин до оси заклепки составляет $L_{n} / 2$. 


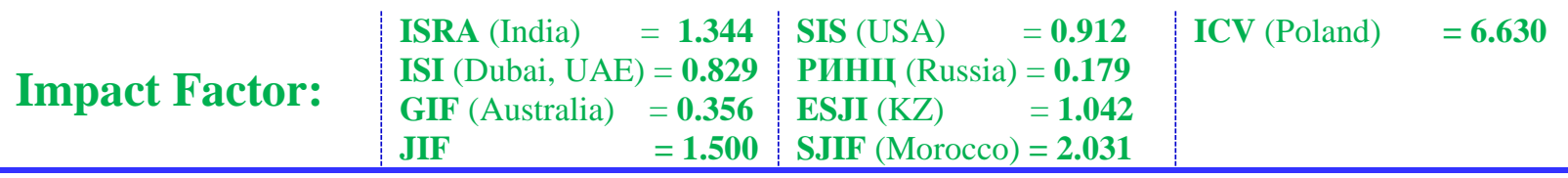

\section{References:}

1. (2015)

Zaklepka.

Available:

https://ru.wikipedia.org/wiki/Заклёпка

(Accessed: 09.09.2015).

2. (2015) Klepanye ili zaklepochnye soedineniya. Available: http://k-a-t.ru/detali_mashin/14dm_klepka/index.shtml

(Accessed: 09.09.2015).

3. (2015) Raschet zaklepochnogo soedineniya. Available:

http://mysopromat.ru/uchebnye kursy/sopromat /sdvig/raschet_zaklepochnogo_soedineniya/ (Accessed: 09.09.2015).

4. (1980) GOST 10299-80. Button-head rivets classes B and C. Specifications.
5. (1980) GOST 10304-80. Rivets classes B and C. General specifications.

6. (1988) GOST 1050-88. Carbon structural quality steel gauged bars with special surface finish. General specifications.

7. (2015) Spravka po SOLIDWORKS. Available: http://help.solidworks.com/2012/Russian/solid works/cworks/IDH_HELP_FATIGUEPLOT.ht m (Accessed: 09.09.2015).

8. (2015) Deformation. Available: http://sopromat.in.ua/textbook/deformatio (Accessed: 09.09.2015). 